\title{
Indirect Speech Utterance: Intersubjective Approach
}

\author{
S. Latysheva \\ Department of Applied Linguistics \\ National Research Technical University \\ Irkutsk, Russia \\ lasveta1@yandex.ru
}

\author{
N. Sivtseva \\ Department of Applied Linguistics \\ National Research Technical University \\ Irkutsk, Russia \\ s_nataly77@mail.ru
}

\author{
S. Fetisova \\ Department of Applied Linguistics \\ National Research Technical University \\ Irkutsk, Russia \\ s_fetisova@mail.ru
}

\begin{abstract}
This work is a study of indirect speech utterance (ISU) introduced by the reported speech construction (RSC) "Agence + Speech Verb + Subordinate Clause", and it represents the way of categorization of the communicative situation. The study uses the intersubjective approach to investigate the semantics of ISU, and it considers the interrelation between the two Self-conceptions as the factor influencing the use of grammatical forms in the clause of RSC, i.e. the relation between ISU Author and a person or a personified phenomenon that is the cause of creation of RSC. Thus, RSC categorizes the communication in its full functioning reporting not only words and meanings. It is an interpretation of minds or the understanding of the mental process and the mutual influence of an individual and its environment, revealing the cognitive basis of any speech act interpretation. The SELF-conceptions of ISU Author and the author of the original utterance (ISU Causator) represent the interpretation of the communicative effect built into the complex of environmental impacts forming the context of perception.
\end{abstract}

Keywords- intersubjective approach; indirect speech utterance; reported speech construction; communicative situation; environment; causation.

\section{INTRODUCTION}

Indirect speech studies comprise a wide range of approaches, from the traditional framework of formal syntax of a complex sentence to the speech acts theory and the deictic theory. On the one hand, this academic diversity proves that indirect speech utterance (ISU) is a complicated phenomenon, and it has grammatical, cognitive, psychological, and sociological layers. On the other hand, the majority of indirect or reported speech research indicates the lack of convergence between the ISU properties found in ESL/EFL grammar books and in real life. The absence of integrity in ISU description results from the ambiguity of the factors determining its semantics. The key questions that the researchers try to answer are what ISU really reports and why it reports this. Most of
ISU studies suggest that it is the speaker's responsibility. Depending on his or her intention, ISU is supposed to "recreate the atmosphere originally present" or to give a "flat" depiction of the event [5]. Therefore, the idea of something basic like event description and something concomitant like original atmosphere leads to the conclusion that ISU is a categorization of the communicative event. The category features are the significant factors determining the ISU semantics.

As it follows from the ISU abstracts, these factors are rather diverse by nature, but they all affect the grammatical forms of the clause of RSC. They can be amorphous and referred to as "certain factors" [4], or they can attribute to some specific characteristics of communicative situation, i.e.:

1) the attitude of ISU Author to ISU content, e.g. representing its verity [8];

2) the reporting methods employed by ISU Author for different types of dialogues [15];

3) the power of someone else's words [3].

The functional unity of the factors discussed above needs a wholistic model of ISU description. Consequently, the grammatical categories of ISU, such as the aspectual forms of the predicate in its subordinate clause, are to match the categories of the communicative situation. In order to work out the wholistic descriptive model of ISU, let us examine the approaches to the indirect speech studies and divide them chronologically into traditional and contemporary ISU description models.

The traditional approaches introduce the classical opposition of structural and psychological models of ISU. They also include the sociological approach aimed at sorting out the differences of positivism and individualism in the indirect speech research. The contemporary approaches to ISU description involve the anthropocentric methods of linguistic 
analysis, employing the cognitive semantic and pragmatic categories to explain the linguistic phenomena. To reveal the relevant ISU features categorizing the communicative situation, let us review the frameworks of traditional and contemporary approaches.

\section{THE TRADITIONAL ISU MODELLING: STRUCTURAL, PSYCHOLOGICAL, AND SOCIOLOGICAL APPROACHES}

The scope of the studies on the forms of reported speech in European languages including ISU goes back to the first quarter of the twentieth century and has resulted in a series of significant contributions to the philological, semiotic, and linguistic fields. Traditionally, ISU presented by RSC contrasts with a number of alternative ways of transferring someone's utterance referred to as direct speech or its modifications (experienced speech, inner monologue, free indirect speech, etc.). Besides, the traditional methods of ISU analysis depend on a specific author; though, the two major trends are distinguished. They are objectivistic or structural and individualistic or psychological approaches.

The first approach, inspired by the ideas of positivism and is carried out by the school of Charles Bally, focuses on the contrast of the syntax structures, their elements and functions. According to this approach, the main characteristic of ISU is the hypotaxis of the main clause (the narrative comment) and the subordinate clause (the content of an utterance). All subjective or cognitive features are supposed to be insignificant, so they leave out the analysis, as they, according to $\mathrm{Ch}$. Bally, do not have any consistent way of linguistic representation [2].

The criticism of Bally's approach bases on the idea that "nothing can form and flourish where there are only linguistic forms" [12]. The second approach is opposed to the formal view of ISU because it puts psychological aspects in the focus of the analysis. The followers of Karl Vossler, Gertraud Lerch and Etienne Lorck, advocating the principles of idealism, employed affect, fantasy, empathy, and a sense of style as the category features for ISU analysis. The authors believe that these psychological categories rest on experience, so they are less typical of ISU because indirect speech is only a reported message in comparison with live and bygone direct speech [9; 10]. Indirect speech is far from reality and from the very fact of speech, so it does not contain any specific impression because the reporting verb shifts the responsibility from the speaker to the subject of the verb of speech. For this reason, it is not evident if it is the speaker's words or only thoughts because the subject of speech verb is not the speaker. Therefore, the subject of speech cannot be the subject of sense perception [10].

The idea of different subjective positions or different voices represented by somebody's own words or ideas and the ones of the others corresponds to the theory of internal dialogism or polyphony developed by Mikhail Bakhtin. His philosophical and literary analysis gives the understanding of literary text as a phenomenon representing many different voices unmerged into a single perspective and not subordinated to the voice of the author. Each voice has its own value and narrative weight within the text. The description of language forms as an interaction of distinct ideologies opens the new era of ISU research.

According to Bakhtin, things do not exist "in themselves", but only in their relations. Being is always an "event" or "cobeing", simultaneous with other beings. In a text, the relations occur through the location of particular authors in their spatial and temporal context, so they construe the meanings together in the interconnection with each other [1]. These concepts give rise to the sociological approach to the ISU analysis suggested by Valentin Vološinov, who considers any utterance to be a part of the continuing cognitive speech interaction and believes that ISU represents one of the forms of utterance interaction [13]. His approach views ISU as a reaction of one language form to another. This reaction depends on the social patterns of speech perception. The author defines his approach as social-objective; therefore, he avoids mentioning in his analysis any characteristics of a cognizer.

It may seem that the interaction happens not between some speakers but between their speech patterns. Vološinov sees the active relation of one utterance to another in the forms of reported speech. According to this, the forms depend on the ways of speech perception; that means some personal speech perceiving. Thus, Vološinov does not mention any perceiving individual or a cognizer. Instead, he writes about "an objective document of perception" that is the evidence of constant social patterns which exist independently. Nevertheless, the author admits that the modification of someone's utterance results from "the material of inner speech" as a speaker takes guidance in its context, so this material influences the methods of building the borrowed speech into the speaker's utterance. This process has two directions; they are the internal reporting and the real commenting. The internal reporting, according to the author, means preparing the conversational turn. The real commenting is the activation of linguistic and extra linguistic experience of a speaker resulted from the specific conditions of communication. These two directions determine the surrounding of the borrowed speech, and Vološinov calls it 'the author's' context. Each of these two directions or factors may be more or less influential in the process of speech reporting, so the relations between the borrowed speech and the author's context are very dynamic and complicated. This dynamism is the reflection of another vital phenomenon, i.e. people's communication. Thus, there is the third factor determining the utterance relations. That is an addressee of the reported speech. Vološinov thinks that this factor depends on the inner speech perception, but it still matters because 'any reporting is made on some purpose' [13].

The work of Valentin Nikolayevich Vološinov, with no doubt, was in advance of his time. In spite of paying little attention to the cognitive and intentional factors in reported speech modelling, he managed to show the ways of applying the speech acts theory and the deictic theory to his approach. As a part of the paradigm of his age, his work criticized subjectivism in the utterance theory when the social determinants of an utterance are not in the focus of the analysis. So some contradicting theses of his work may become logical if supported by the modern linguistic and cognitive theories. For example, if the terms "inner speech, author, and dynamism" are replaced by "human intellect, 
verbal and cogitative subject, and cognition", the ambiguous aspects become distinct. Indeed, the idea of anthropocentrism may help to realize that a pure interaction of language forms, representing some abstract entities, has no meaning without a speaker, who can interpret them. They are speakers, who interact, and their interaction is a result of the social identity of human language. Consequently, Vološinov makes a hypothesis that the forms of reported speech are socially determined, and they illustrate the trends of mutual social guidance of speakers [13].

The way of interaction between the author's and the borrowed utterances depends on the degree of explication of the two basic components in the language forms. Vološinov calls these components 'what-of-speech' and 'how-of-speech', and they represent what a speaker means and how he formulates this meaning. The author examines which of them dominates in the Russian, French, and German languages; then, he reveals the types of social ideology in communication (authoritarian dogmatism, realistic and critical individualism, relativistic individualism). He also employs the method of contrastive analysis and explains the differences between ISU in English and Russian with the help of socio-historical factors. For example, he believes that the tense shift in English ISU takes place because, unlike Russian, there was the period of Cartesian rationalism in English "when rational, self-reliant, and fact-based 'author's context' disjointed the borrowed speech components and created complex and sophisticated modifications of reported speech" [13]. According to this, the basic meaning of RSC is the analysis of both the "what-ofspeech' and the 'how-of-speech' of reporting utterances. The changes of these two components have different language representation. The emotional elements of the 'how-ofspeech', which express speaker's intentions, become the speech content or modify a reporting verb. The analysis may address the referents of the reported utterance or the characteristics of the speaker; therefore, Vološinov differentiates between the two modifications of reported speech; they are referent-analytical and word-analytical. The first modification leaves the meaning of the reported utterance untouched and impersonalizes it. The second one, on the contrary, keeps the original utterance highly individual and neutralizes the personal senses of ISU author.

Taking into consideration all the previously mentioned information, the traditional ISU analysis constitutes the grounds for the cognitive approach to the communicative situation categorization by stating the multilayered status of an utterance and coming up with its viewing as a cognitive speech interaction. It reveals a set of relevant features, such as different viewpoints confronting in the language forms, reported speech addressee, the surrounding of the borrowed speech or the author's context, and the author's attitude to the reporting content. Nevertheless, the structural and psychological approaches have a considerable influence on the contemporary ISU modelling.

\section{THE CONTEMPORARY APPROACHES TO ISU MODELLING}

The data of contemporary grammar books of the English and Russian languages, both academic and practical, prove that the objectivistic approach has a great impact on the ISU research. For example, the Russian academic grammars define the reported speech as the complex sentence with a complement clause, and they view it as a grammatically organized transformation of direct speech. In the same way, the English grammar textbooks provide the mechanical rules to carry out these transformations, such as "one tense back rule". A number of works conveying the criticism of the reported speech presentation to students encourage considering the semantics of the situation represented by RSC rather than automatically apply the Sequence of Tenses Rule. One of them is the article of George Yule, Terrie Mathis, and Mary Frances HopKins where the authors "present a range of examples from written and spoken discourse to illustrate how speakers and writers report what was said using forms and structures that receive virtually no coverage in the textbooks available to English language learners" [15]. Thus, the idea of assimilating some mechanical rules for the conversion of one structural form of report into another gives a one-dimensional view of RSC that does not correspond with the wholistic trends of modern linguistics, so the problems of ISU is still challenging. To investigate ISU semantics for the purpose of adequate explanation of RSC grammar, the contemporary research engages alternative approaches.

The last decades saw a number of works revealing the cognitive and anthropocentric nature of ISU. They employ various cognitive and pragmatic factors as semantically relevant categories to explain ISU forms.

One of the popular theories is the theory of deixis that has a pragmatic nature as it is connected with the relations between the structures and the context of their usage. Moreover, in the frames of the given theory, the scientists investigate the language expressions and utterances that can be interpreted only if one takes into consideration three main aspects of the communicative act: its participants, time and place [28].

The deictic theory is a widely applied approach to enrich the description of RSC grammatical properties. It shifts the research focus from the formal syntax rule-based structures to the cognitive characteristics of ISU Author, such as his or her personal viewing of time, space and reporting situation. Elizabeth Goodell suggests that the factor determining the reported speech changes is a "spatiotemporal" point of view for the reporter. The elements of RSC such as pronouns, verbs, and adverbs from the original utterance "must conform to the here and now of the act of reporting. Whether or not this necessitates a change from the original utterance depends on the relevance of the pointing (deictic) qualities of these words for the present act of reporting" [5]. The later work of this author studying the children's deictic changes signalling direct or indirect speech singles out another significant factor, i.e. the vantage point presented by ISU and addressed to the listener. She describes this category as a complex competence taking years to acquire [6].

The deictic framework of ISU description suggested by Alexander V. Kravchenko views RSC as a transformation of the direct speech construction. To carry out this transformation, a speaker should be aware of the original utterance index. This index is a set of relevant factors, which 
characterize the context of using this utterance, such as the author of the utterance, the addressee, and the time of conversation [23]. The indication to the previous segment of the discourse (intrastructural index) means splitting the subject of speech into two entities; therefore, a speaker and a watcher have appeared. According to A. Kravchenko, the ISU author appropriates the language at the moment of speaking, and he is only able to use the phenomenological knowledge of a person, who is a watcher, to make his utterance on its basis [23]. This thesis entails the work of Anzhelika Matienko, who writes that the grammatical forms of the subordinate clause in RSC are determined by the correlation of the two pragmatic factors that are the subject of perception and the subject of speech [25]. She supposes that ISU is a form of narrative. Therefore, ISU is opposed to the ordinary situation of verbal communication.

The alternative method of comprehension of the semantics of ISU is to incorporate it into some broader category. For example, Elena Paducheva views ISU as a property of narrative, and she points out that the indirect speech is pragmatically ambivalent. It can be a part of narration; also, ISU functions in the conversational discourse. Therefore, the author separates ISU from the two opposed regimes of interpretation (narrative and speech). She defines the special status of ISU as "the regime of syntactic interpretation", and she underlines that the subject of cognition, in this case, is not a speaker, but a person, who is the referent of the grammatical subject [26].

The work of Anna Wierzbicka brings ISU into dramaturgy. She states that behind all types of reporting including RSC lies a concern to dramatize the words of an earlier speaker/author to a later audience. The ISU Author temporary assumes the role of that other person, imagines himself as the other person and for a moment behaves in accordance with this counterfactual assumption. He takes the persona of the original speech-event dramatically reenacting it so that the two voices merge into one [14].

A number of works investigate ISU within the categories related to the concept of verity. For instance, the study of semantic and syntactic components of ISU by Zhana Ivanova shows that it has at least two propositions. There is a propositional actant with ambiguous meaning in ISU called "speech content". On the one hand, the shift of verb forms in the subordinate clause expresses the semes "NOT-ME" and "PREVIOUS SPEECH ACT". According to this, the source of information has the marker of abstract grammatical meaning, indicating ISU Author receives the information from another person. Thus, the retelling form of the verb combined with the lexical means of nomination receives the additional semes denoting the degree of credibility [19]. Besides the semantic and syntactic structure, the author describes lexical and grammatical markers of reported evidence in Russian and Bulgarian referred to as evidential lexemes. She argues that they are the explication of the information source indicators related to the category of retellingness, which is a sub category of evidentiality [20].

Another category associated with the concept of verity and reality employed by Larisa Volkova to study the semantics of ISU is credibility. The author uses the framework of functional-semantic field of retelling that is a part of the bigger semantic field of indirect evidence. Since indirect speech represents two authors, non-standard structures of ISU belong to the peripheral space of the semantic field, underlining the morphological character of the category of indirectness with its structural coherence, modal meaning of realness, and neutral stylistic connotation. According to this, the semantic fields of indirect speech and of credibility cut each other and have the common space. Moreover, they have similar means of expressing this modal meaning [17].

One more relevant semantic category represented by ISU is the category of author. The research by Olga Kobrina describes ISU as a means of linguistic representation of the authorship, and it shows the consequences of mental operations of a speaker or writer. It is associated with the category of evidentiality, which correlates with the category of modality. These two categories are ontologically close and determined by the process of communication, so their linguistic representations in ISU are complementary [21].

Summarizing the contemporary approaches to ISU modelling, one can see the two opposed trends of its investigation and description. The first general approach is the inductive method of placing ISU to broader notional classes, such as evidentiality, credibility, dramaturgy, and authorship. The second one is the deductive method disclosing the categories that compose and determine the semantics of ISU, e.g. spatiotemporal viewpoint of ISU Author, the original utterance index, and the split of the speaking subject. This means that ISU, as a way of categorization of communicative situation, represents simultaneously the procedures of analysis and synthesis. Therefore, ISU modelling lacks this significant characteristic, and the new development of ISU analysis supplies the intersubjective approach.

\section{THE INTERSUBJECTIVE ISU MODEL}

The term "intersubjectivity" refers to relation between people. The concept of social relations knits the reported speech research advocating the idea that reporting somebody's words represents interaction. For example, Elizabeth Holt argues that reported speech combines the design features of the former utterance replaying its locution, and the sequential environments in which ISU occurs. It means that the speaker simultaneously conveys his or her assessment of the original utterance while reproducing it by various language means, from the prosodic structure to implicit comments [7].

The concept of reported speech interaction entails the idea of causation between the two communicative events. The original utterance demonstrating the communicative behaviour of its author causes the reaction of another person. This person starts interpreting the complex of impacts, i.e. verbal design of the original utterance, non-verbal signals of the speaker, his or her intentions and thoughts, the context of their social relation, etc. Depending on the communicative situation, ISU Author articulates the interpretation of these complicated and interrelated factors attaching his or her attitude. Therefore, the intersubjective ISU model comprises the two subjects and their relation in the context of mind and behaviour interpreting. 
ISU is a linguistic representation of people's communication that is the basis of human intellect. Therefore, ISU reveals a set of cognitive actions, represented by the language forms. Language is an activity, so speaking has an intellectual and informational impact on the environment, which the speaker interacts with, and it results in the changes of this environment. Consequently, a speech act correlates with the cause-effect process or the causation of "an event or a condition coming from an initiative and active individuum" [22]. This consideration gives the view of ISU in the framework of mutual determination of an individuum and an environment. Other people's speech is also a part of this environment.

According to this, ISU correlates with the theory of autopoiesis, developed by Humberto Maturana and Francisco Varela in their biocognitive theory of language [11]. In this case, the ISU model will reflect the cognition process that is the codetermination of an individuum and its environment, including communication impacts. On the one hand, ISU Author is both the subject of self-reflection and the object of environmental impacts, which include people's speech. On the other hand, he or she constructs the connections with the environment as a self-generating feedback system that is the system of his or her personal values, influenced by environment. So the environment and the individuum are not opposed, they are connected and co-determined. That is why, the border between a Self and its surrounding is not clear. This thesis accords with the concept of intersubjectivity that reveals the deep determination of external and internal events as the processes and the results of cognition are united, and the subject and the object of interpretation fuse making a circle of creativity.

There are numerous language facts to prove the idea that any non-verbal environmental impacts are able to become the sources of causation interpreted by an individuum with the help of speech verbs. These impacts can be audial, visual or any other type of perceptional impressions, for example:

(1) A sudden yelp told her she had done her job (Rowling);

(2) The tears told coach John McGroaty that Olandis Gary was special (COCA).

Consequently, it is not enough to study the speech act representations depending on the speech content, the addressee/addresser characteristics and other conventional parameters mentioned in the review above. To describe the meaning of an utterance inside another utterance, it is relevant to include the communication act into the complex of interactions between an individuum and environment in their mutual causation. As a type of communication acts, ISU has a number of features that help to make the process of communication effective and adequate. The effectiveness of communication correlates with the impact efficiency and with getting the addressee's reaction, desired by the addresser. This means that the stimulus more or less determines the certain type of reaction, so it programmes the reaction at a certain degree [16]. In addition to a verbal representation of some meaning, the interpreter of the speech impacts perceives a complex of supplementary environmental influences. Put on this background, the interpreted speech may differ from its anticipated meaning.

In (3), one can see the interpretation of the boy's behaviour who is giving a command "Up!" to perform a fly on the magic broom. The meaning of the stand-alone speech act makes us believe that this boy wants to fly. Consequently, this means that the interpretation of the speech act is to express the speaker's desire to soar up in the air. However, one observes the opposite meaning in the example:

(3) There was a quaver in Neville's voice that said only too clearly that he wanted to keep his feet on the ground (Rowling).

The ISU author, who is also the interpreter of the boy's speech, shows the opposite meaning in his utterance, and this interpretation is adequate because the complex of external and internal factors, more relevant in comparison with the speech content, determines it. They are the non-verbal signals (a quaver in the speaker's voice) and the personal communication experience based on the previous interaction of ISU author with the speaker.

\section{CONCLUSION}

The intersubjective approach to the ISU studies allows one to extend considerably the field of analysis and to adjust the differences of traditional approaches discussed above.

Firstly, the ISU construction "Agence + Speech Verb + Subordinate Clause" represents both verbal and non-verbal impacts. ISU Author interprets these impacts in the context of the situation where they are performed and perceived.

Secondly, ISU author interprets not only explicit verbal and non-verbal behaviour of the speaker. He also interprets the implicit activity hidden in the speaker's mind. As human mind and language are inseparable, mental activity correlates with speech acts [27].

Language, mind and communication are like the three sides of a pyramid with a human being at its bottom. These three sides have common borders, so they are the entire. At the utterance level, there is a sentence on the language side, there is modality on the mental side, and the communication side has a speech task or a motive [24]. The similar idea about the two frames of a sentence suggests the thesis of Vladimir Gak, who called them modal and communicative frames [18].

Therefore, ISU is not a simple transformation of someone's utterance. It is the categorized speech act, the meaning regeneration in accordance with the following factors:

1) The original utterance has an intellectual and informational impact, and it is built into the complex of environmental impacts forming the context of perception. The interpretation of the utterance content is inseparable from interpretation of these impacts.

2) ISU has a metacommunicative level that is the level of two SELF-representations expressed in their comparison or contrast. They are the SELF-conceptions of ISU Author and the author of the original utterance (ISU Causator). 


\section{References}

[1] M. Bakhtin, The Dialogic Imagination. Four Essays. Translated by C. Emerson and M. Holquist, Texas: University of Texas Press Slavic Series, 1982.

[2] Ch. Bally, L'expression des idees des sphere personelle et de solidarite dans les langues indo-europeennes, Aarau: Verlag H.R. Sauerlander \& Co., 1926, pp. 68-69.

[3] R. Buttny \& P.L. Williams, "Demanding respect: The uses of reported speech in discursive constructions of interracial contact," Discourse and Society, vol. 11 (1), pp. 109-133.

[4] R. Declerck \& K. Tanaka, "Constraints on tense choice in reported speech,” Studia Linguistica, vol. 50 (3), pp. 283-301.

[5] E.W. Goodell, "Integrating theory with practice: An alternative approach to reported speech in English," TESOL Quarterly, vol. 21 (2), pp. 305325 .

[6] E.W. Goodell \& J. Sachs, "Direct and indirect speech in English-speaking children's retold narratives," Discourse Processes, vol. 15 (4), pp. 395-422.

[7] E. Holt, "Reporting and reacting: concurrent responses to reported speech," Research on Language and Social Interaction, vol. 33 (4), pp. 425-454.

[8] G. Jacobs, "Tense choice in English past reported speech," Leuvense Bijdragen, vol. 88, pp. 51-67.

[9] G. Lerch, The improperly direct speech in French, Heidelberg: Karl Winter, 1920.

[10] E. Lorck, The "experienced speech"; a linguistic examination, Heidelberg: Karl Winter, 1921.

[11] U.Maturana, F.Varela "Autopoiesis and cognition:the realization of the living", Boston: Studies in the philosophy of science, 1979.

[12] A. Ponzio \& S. Petrilli, "Visions of the other and free indirect speech in artistic discourse," International Handbook of Semiotics, pp. 181-201, 2005.

[13] V.N. Vološinov, Marxism and the Philosophy of Language. Translated by L. Matejka and I.R. Titunik, Michigan: University of Michigan, Department of Slavic Languages and Literatures, 1972.

[14] A. Wierzbicka, "The semantics of direct and indirect discourse," Paper in Linguistics, vol.7 (3-4), pp. 267-307.
[15] G. Yule, T. Mathis \& M.F. HopKins, "On reporting what was said" in English Language Teaching Journal, vol. 46 (3), pp. 245-251.

[16] N. Arutyunova, Language and human world, Moscow: Yazyki russkoi kultury, 1999.

[17] L. Volkova, "The category of evidentiality in the German and Russian languages" in Russian and Comparative Philology: Contemporary State and Perspectives, Kazan: KFU, 2004, pp. 136-137.

[18] V. Gak, "Utterance and situation" in The Problems of Structural Linguistics, Moscow: Nauka, 1973, pp. 349-373.

[19] Zh. Ivanova, "The types of reproduced speech" in The Problems of Cognitive and Functional Description of the Russian and Bulgarian Languages, issue II, Shumen. 2003.

[20] Zh. Ivanova, "On the markers of evidentiality in the Russian and Bulgarian languages," The Russian Word on the Balkans, Shumen: Faber, 2011, pp. 53-61.

[21] O. Kobrina, "On the combinability of the communicative categories of evidentiality and modality" in The Conceptual Space of Language, Tambov: TSU, 2005, pp. 404-413.

[22] L. Kovaleva, "The role of English causative constructions in the representation of the concept of causation," The Linguistic Paradygms and Linguodidactics, Irkutsk: BSUEL, 2006, pp.83-91.

[23] A. Kravchenko, The issues of the indexicality theory, Irkutsk: ISU, 1992.

[24] S. Latysheva, The modus of indirect speech utterance and its influence upon the aspectual form of the predicate in the clause, Irkutsk: ISLU, 2008.

[25] A. Matienko, The functional peculiarities of the indexical elements of the reported speech utterances in the modern English language, Irkutsk: ISLU, 1998.

[26] E. Paducheva, Semantic research (Tense and aspect semantics in the Russian language; Semantics of narrative), Moscow: Shkola "Yazyki russkoi kultury", 1996.

[27] N. Ryabtseva, Language and natural intelligence, Moscow: Academia, 2005.

[28] N. Stetsenko, The observer's role in the conceptualization of the beginning and end in the modern English language (exemplified in nouns), Irkutsk: ISLU, 2004. 